DOI: https://doi.org/10.24127/ajpm.v9i3.2957

\title{
PERANGKAT PEMBELAJARAN MODEL PROBLEM BASED LEARNING MEMFASILITASI KEMAMPUAN PEMECAHAN MASALAH MATEMATIS PADA MATERI ARITMATIKA SOSIAL
}

\author{
Nuraini $^{1}$, Maimunah ${ }^{2}$, Yenita Roza $^{3}$ \\ ${ }^{1,2,3}$ FKIP Universitas Riau, Pekanbaru, Indonesia \\ *Corresponding author. Address, Postal code, City, Country. (9pt) \\ E-mail: $\quad$ nuraininadhifa@yahoo.com ${ }^{1)}$ \\ $\underline{\text { maimunah@lecturer.unri.ac.id }}^{2)}$ \\ yenita.roza@lecturer.unri.ac.id ${ }^{3)}$
}

Received 20 July 2020; Received in revised form 13 September 2020; Accepted 23 September 2020

\begin{abstract}
Abstrak
Tujuan penelitian ini adalah untuk mengembangkan perangkat pembelajaran model problem based learning yang memfasilitasi kemampuan pemecahan masalah pada materi aritmatika sosial. bagi siswa SMP kelas VII. Jenis penelitian adalah penelitian pengembangan atau Research and Development (R\&D). Model pengembangan yang digunakan adalah model 4-D. Instrumen penelitian ini adalah lembar validasi, lembar pratikalitas dan tes kemampuan pemecahan masalah matematis (KPMM). Data dianalisis menggunakan kriteria validitas untuk perangkat seperti Siabus, RPP , LKPD, tes KPMM, dan kriteria pratikalitas dari hasil angket respon peserta didik. Hasil rata-rata persentase yang diperoleh dari validitas Silabus yaitu 87,08\% memenuhi kriteria sangat valid, RPP memenuhi kriteria sangat valid yaitu 86,10\%, LKPD memenuhi kriteria sangat valid yaitu 86,14\% dan untuk Soal Kemampuan Pemecahan Masalah Matematis yaitu $85,42 \%$ dengan kriteria sangat valid. Hasil uji pratikalitas kelompok kecil terhadap LKPD diperoleh rata-rata persentase 93,54\% memenuhi kriteria sangat praktis. Berdasarkan analisis hasil validitas dan praktikalitas pada penelitian ini adalah perangkat pembelajaran matematika berupa Silabus, RPP, LKPD dan Soal Kemampuan Pemecahan Masalah Matematis pada model Problem Based Learning sudah memenuhi kriteria valid dan praktis, sehingga dinyatakan bahwa perangkat tersebut dapat digunakan dalam pembelajaran matematika pada materi aritmetika sosial.
\end{abstract}

Kata kunci: Aritmatika sosial; kemampuan pemecahan masalah matematis; perangkat pembelajaran matematika; problem based learning.

\begin{abstract}
The purpose this study was to develop problem based learning models that facilitate problem solving skills in social arithmetic for grade VII Junior High School students. This type of research $i$ Research and Development $(R \& D)$. The development model type of research is the 4-D models. The research instruments were validation sheet, a practicality sheet and a mathematical problem solving ability test (KPMM). Data were analyzed using validity for tool such as Syllabus, RPP, LKPD, KPMM test, and practical criteria from the result of student response questionnaire. The average percentage result obtained from the validity od the syllabus is $87,08 \%$ which meets the very valid criteria, the RPP meet the very valid criteria, namely $86.10 \%$, the LKPD meet the very valid criteria namely $86.14 \%$ and for the Mathematical Problem Solving Ability Problem, it is $85,42 \%$ with very valid criteria. The results of the small group practicality test on LKPD obtained an average percentage of $93.54 \%$ fulfilling the very practical criteria. Based on the analysis of the results of validity and practicality in this study, mathematics learning tools in the form of syllabus, lesson plans, student worksheets and mathematical problem solving abilities in the Problem Based Learning model have met the valid and practical criteria, so that it is stated that these devices can be used in mathematics learning in arithmetic material. social.
\end{abstract}

Keyword: Mathematical problem solving ability' mathematics learning tools; problem baseb learning; social arithmetic. 
DOI: https://doi.org/10.24127/ajpm.v9i3.2957

\section{PENDAHULUAN}

\begin{tabular}{lrr}
\multicolumn{2}{c}{ Kurikulum merupakan } & acuan \\
dalam penyelenggaraan & sistem \\
pendidikan. $\quad$ Kurikulum & berisi
\end{tabular} seperangkat rencana dan pengaturan mengenai tujuan, isi, dan bahan pelajaran serta cara yang digunakan sebagai pedoman penyelenggaraan kegiatan pembelajaran untuk mencapai tujuan pendidikan tertentu. Tanpa kurikulum yang sesuai dan tepat, maka suatu tujuan dan sasaran dari pendidikan, akan sulit untuk dicapai. Lahirnya Kurikulum 2013 pada dasarnya merupakan salah satu upaya untuk memperbaiki mutu pendidikan di Indonesia.

Dalam implementasinya banyak hal yang harus dicermati dan dipersiapkan, terutama dalam mempersiapkan perangkat pembelajaran yang digunakan oleh guru untuk melaksanakan proses pembelajaran did kelas. Selama ini, guru hanya dituntut untuk menyusun RPP dengan silabus sebagai pedoman pembuatan telah disiapkan oleh Pemerintah Pusat. Pada Kurikulum 2013 silabus belum dirancang oleh Pemerintah. Pemerintah hanya memberikan Permendikbud yang berisi kompetensi-kompetensi dasar yang harus dikuasai para peserta didik sesuai dengan mata pelajaran. Para guru dituntut untuk menyusun perangkat pembelajaran dengan berpedoman pada Permendikbud yang telah diberikan oleh Pemerintah.

Perangkat pembelajaran harus dipersiapkan sehingga pelaksanaan pembelajaran lebih terarah untuk mencapai kompetensi yang diharapkan. Guru yang baik harus menyusun perencanaan sebelum melaksanakan pembelajaran di kelas. Proses pembelajaran yang baik harus didahului dengan persiapan yang baik, karena tanpa persiapan yang baik sulit rasanya menghasilkan pembelajaran yang baik. Suatu keharusan bagi guru sebelum mengajar terlebih dahulu menyusun perencanaan atau perangkat pembelajaran. Salah satu perangkat pembelajaran yang harus ada pada setiap proses pembelajaran adalah Silabus, Rencana Pelaksanaan Pembelajaran (RPP) dan Lembar Kerja Peserta Didik (LKPD).

Menurut Sofan Amri (2013) RPP dijabarkan dari silabus untuk mengarahkan kegiatan belajar peserta didik dalam upaya mencapai kompetensi dasar. Setiap guru berkewajiban menyusun RPP secara lengkap dan sistematis agar pembelajaran berlangsung secara interaktif, inspiratif, menyenangkan, menantang, memotivasi peserta didik untuk berpartisipasi aktif. Agar terciptanya pembelajaran yang baik, maka guru juga harus memberi kesempatan bagi peserta didik untuk berperan aktif dan kreatif dalam mengeksplorasi kemampuan disetiap proses pembelajaran. Salah satu alternatif yang dapat digunakan guru untuk mendukung situasi dan kondisi pembelajaran yang demikian adalah dengan penggunaan LKPD.

Beberapa faktor yang dapat mempengaruhi pencapaian kompetensi dalam proses pembelajaran berupa metode pembelajaran dan ketersediaan bahan ajar serta perangkat yang digunakan dalam proses pembelajaran di sekolah (Syawahid \& Putrawangsa, 2017). Ketersediaan LKPD yang dapat dipergunakan oleh peserta didik dalam proes pembelajaran akan berdampak langsung oleh seluruh peserta didik (Haryani, Wardani, \& Prasetya, 2016).

Ketersediaan LKPD dapat membantu peserta didik sangat diperlukan dalam proses pembelajaran (Andatari \& Komsiatun, 2018). 
Perangkat pembelajaran yang mampu memotivasi peserta didik dalam proses pembelajaran yang berlangsung didalam kelas salah satunya adalah LKPD (Wahyuni, Masykur, \& Pratiwi, 2019)

Lampiran Permendikbud Nomor 58 Tahun 2014 tentang kurikulum SMP dijelaskan bahwa salah satu tujuan pembelajaran matematika yaitu memecahkan masalah, penalaran serta mampu menyusun bukti matematika dengan menggunakan kalimat lengkap, simbol, tabel, diagram, atau media lain untuk memperjelas keadaan atau masalah.

Penelitian ini sejalan dengan Ramirez, Shaw, \& Maloney (2018) yang menyatakan bahwa penggunaan perencanaan perangkat yang sesuai mampu menunjang proses pembelajaran sehingga memperoleh hasil yang maksimal. Penelitian ini juga senada dengan hasil penelitian Agrawal \& Morin (2016) yang menyatakan bahwa perencanaan perangkat pembelajaran yang digunakan dalam aktivitas belajar mengajar dapat membantu serta mempermudah menghubungkan konteks dunia nyata dengan pengetahuan yang diperoleh sebelumnya, saat ini dan yang akan diperoleh yang akan datang. Pencapaian hasil yang maksimal dalam proses pembelajaran sangat ditentukan oleh perencanaan perangkat yang telah disusun oleh guru untuk digunakan di dalam kelas saat proses pembelajaran berlangsung. (Indriani, 2017).

Kemampuan pemecahan masalah matematika merupakan salah satu kemampuan yang sangat penting yang harus dimiliki oleh peserta didik dalam menyelesaikan suatu permasalahan (Mukasyaf, Fauzi, Mukhtar, 2019). Son, Darhim, \& Fatimah, (2020) mengungkapkan bahwa untuk menyelesaikan permasalahan matematika dibutuhkan aplikasi strategi dalam penyelesaian suatu permasalahan yang mampu mengorganisir serta mengarahkan pemecahan permasalah untuk mengekplorasi beberapa gagasan.

Kenyataan dilapangan bahwa kemampuan pemecahan masalah matematis (KPMM) ini sangat sulit untuk dikuasai oleh peserta didik dan masih tergolong sangat rendah. Hal ini sejalan dengan hasil penelitian oleh Kenedi, Hesa, Ariani, Zainil \& Hendri (2019) yang menyatakan bahwa KPMM peserta didik di sekolah masih tergolong sangat rendah. Hal ini ditunjang hasil penelitian Son, Darhim, \& Fatimah, (2020) yang menyatakan bahwa sebagian besar peserta didik memiliki KPMM yang sangat rendah.

Dindyal, Guan, Lam, Hoong \& Seng (2012) mengungkapkan bahwa KPMM adalah kemampuan pengetahuan yang sangat rumit untuk dimengerti oleh peserta didik. Menyelesaikan soal pemecahan masalah matematis merupakan kegiatan yang sangat sulit dalam menyelesaikan beberapa permasalahan (Garcia, Boom, Krosbergen, Nunez, \& Rodriguez, 2019). KPMM harus menjadi perhatian agar dapat melakukan tindak lanjut dari suatu penelitian (Arjudin, Sutawdjaja, Irawan, \& Sa'adijah, 2016).

Peserta didik akan mudah untuk menemukan penyelesaian dari suatu permasalahan apabila dikaitkan dengan dunia nyata mereka. Tujuan pembelajaran dapat dicapai secara maksimal apabila model pembelajaran yang digunakan sesuai dan tepat. Pemilihan model pembelajaran matematika yang digunakan guru memiliki peran yang sangat penting. Salah satu model pembelajaran yang dapat melatih peserta didik memecahkan masalah, penalaran serta mampu menyusun bukti matematika 
dengan menggunakan kalimat lengkap, simbol, tabel, diagram, atau media lain untuk memperjelas keadaan atau masalah adalah Problem Based Learning, (Verra Novia, 2016).

Menurut Choridah (2013) karakteristik pembelajaran berbasis masalah adalah belajar dimulai dengan suatu permasalahan. Dengan permasalahan tersebut, peserta didik akan memperdalam pengetahuannya tentang apa yang mereka ketahui dan apa yang mereka perlu ketahui untuk memecahkan permasalahan. Selain itu karakteristik model pembelajaran berbasis masalah yang berorientasi pada suatu permasalahan yang berhubungan dengan dunia nyata berpengaruh positif terhadap proses berfikir peserta didik. Pengaruh positif pada peserta didik dapat dilihat dari sejauh mana peserta didik dalam mencari dan menemukan penyelesaian suatu permasalahan.

Berdasarkan uraian yang dipaparkan, peneliti melakukan penelitian pengembangan perangkat pembelajaran matematika menggunakan model PBL memfasilitasi KPMM pada materi aritmetika sosial kelas VII Sekolah Menengah Pertama.

\section{METODE PENELITIAN}

$\begin{array}{ccc}\text { Jenis } & \text { penelitian ini yang } \\ \text { digunakan } & \text { adalah penelitian }\end{array}$
pengembangan. Model pengembangan yang digunakan adalah model 4-D merujuk pada teori pengembangan Thiagarajan dan Semmel (Mulyatiningsih, 2014) meliputi define (pendefenisisan), design (perancangan), develop (pengembangan) dan disseminate (penyebaran).

Tahap pendefenisian terdiri dari : (1) Analisis awal-akhir : Peneliti menganalisis ketersediaan dan kesesuaian perangkat pembelajaran yang digunakan di sekolah yang mengacu pada standar proses. (2) Analisis peserta didik yaitu Analisis peserta didik merupakan telaah tentang karateristik peserta didik yang sesuai dengan rancangan dan pengembangan perangkat pembelajaran. (3) Analisis tugas yaitu Analisis tugas merupakan pengidentifikasian tugas atau keterampilan utama yang dilakukan peserta didik selama pembelajaran, kemudian menganalisisnya ke dalam suatu kerangka sub keterampilan yang lebih spesifik. (4) Analisis materi yaitu: Analisis ini bertujuan untuk mengidentifikasi, merinci dan menyusun secara sistematis materi yang relevan yang diajukan berdasarkan analisis awal-akhir, dan (5) Analisis spesifikasi tujuan pembelajaran yaitu: Pada kegiatan ini akan dirumuskan indikator pencapaian kemampuan komunikai matematika dengan mengacu pada kompetensi dasar dan tujuan yang akan dicapai. Setelah adanya indikator maka dapat merumuskan tujuan pembelajaran.

Tahap perancangan terdiri dari (1) pemilihan media yaitu Peneliti menentukan media yang tepat dan sesuai untuk menyajikan materi aritmetika sosial juga sesuai dengan model pembelajaran yang digunakan. (2) Pemilihan format yaitu : Pada tahap ini peneliti memilih format untuk mendesain isi, pemilihan strategi pembelajaran, dan sumber belajar yang sesuai dengan prinsip, karakteristik, dan langkah - langkah yang sesuai dengan model pembelajaran yang digunakan. (3) Rancangan awal yaitu : Desain awal dari perangkat pembelajaran dalam penelitian ini meliputi Silabus, RPP, LKPD dan instrumen tes kemampuan pemecahan masalah matematis. Rancangan yang dihasilkan dinamakan Draft I. 
DOI: https://doi.org/10.24127/ajpm.v9i3.2957

Tahap pengembangan terdiri dari (1) Validasi ahli yaitu : Hasil dari rancangan awal yaitu draft I divalidasi oleh validator, dan revisi digunakan sebagai dasar perbaikan perangkat pembelajaran untuk mendapatkan draft II. (2) Uji coba pengembangan yaitu Draf II diuji coba kelompok kecil untuk mendapatkan masukan secara deskriptif. Uji coba kecil bertujuan untuk menilai keterbacaan LKPD. Peneliti selanjutnya merevisi produk kembali berdasarkan kelemahan-kelemahan yang ditemukan untuk melihat praktikalitas perangkat yang dikembangkan. Khususnya LKPD.

Tahap penyebaran atau

disseminate merupakan tahap penggunaan perangkat yang telah dikembangkan pada skala yang lebih luas, misalnya di kelas lain, di sekolah lain, oleh guru lain. Tapi tahap ini tidak dilakukan.

Instrumen pengumpulan data berupa lembar validasi, dan angket respon peserta didik. Lembar validasi terdiri dari lembar vaidasi silabus, lembar validasi RPP, lembar vaqlidari LKPD, dan lembar validasi tes KPMM. Angket respon siswa digunakan untuk melihat praktikalitas penggunaan LKPD.

Teknik analisis data hasil validasi dilakukan untuk menentukan valid atau tidaknya perangkat pembelajaran. detelah memperoleh data, maka data tersebut kemudian diolah untuk dicari persentase validitas perangkat. Mengacu pada Akbar (2013) untuk diambil kesimpulan berdasarkan kriteria validitas pada Tabel 1. Perangkat pembelajaran dikatakan sudah valid atau dapat dilanjutkan untuk uji selanjutnya, nilai validitas yang harus dipenuhi adalah minimal memperoleh kategori cukup valid. Jika belum memenuhi maka perlu dilakukan revisi dan pengujian ulang sampai valid.
Tabel 1. Kriteria penilaian validitas.

\begin{tabular}{cc}
\hline Interval & $\begin{array}{c}\text { Tingkat } \\
\text { Validitas }\end{array}$ \\
\hline $85,01 \%-100 \%$ & Sangat valid \\
$70,01 \%-85 \%$ & Cukup valid \\
$50,01 \%-70 \%$ & Kurang valid \\
$1 \%-50 \%$ & Tidak valid \\
\hline
\end{tabular}

Hasil analisis lembar pratikalitas mengacu pada Menurut Riduwan (Dalam Giantara, 2013) teknik analisis pratikalitas yaitu :

$P=\frac{\sum \text { skor per item }}{\text { skor maksimum } \times n \text { siswa per item }} \times 100 \%$.

Kemudian diambil kesimpulannya berdasarkan kriteria pratikalitas berdasarkan Tabel 2 .

Tabel 2. Kriteria Penilaian Pratikalitas

\begin{tabular}{cl}
\hline $\begin{array}{c}\text { Persentase } \\
\text { Penilaian }\end{array}$ & \multicolumn{1}{c}{ Kriteria } \\
\hline $85,01 \%-100,00 \%$ & $\begin{array}{l}\text { Sangat praktis, atau } \\
\text { dapat digunakan } \\
\text { tanpa revisi }\end{array}$ \\
$70,01 \%-85,00 \%$ & $\begin{array}{l}\text { Cukup praktis, atau } \\
\text { dapat digunakan } \\
\text { namun perlu direvisi } \\
\text { kecil. }\end{array}$ \\
Kurang praktis, \\
disarankan tidak \\
dipergunakan karena \\
perlu revisi besar. \\
Tidak praktis, atau \\
tidak boleh \\
dipergunakan
\end{tabular}

\section{HASIL DAN PEMBAHASAN}

Penelitian ini merupakan pengembangan perangkat pembelajaran matematika menggunakan Problem Based Learning (PBL) memfasilitasi KPMM pada materi aritmetika sosial di kelas VII SMP yang memenuhi kriteria valid, dan praktis. Perangkat pembelajaran yang dikembangkan yaitu 
Silabus, RPP sebanyak lima pertemuan, LKPD lima pertemuan dan tes tes KPMM sebanyak 4 soal. Perangkat yang dikembangkan terkait dengan KD 3.9 Mengenal dan menganalisis berbagai situasi terkait aritmatika sosial (penjualan, pembelian, potongan, keuntungan, kerugian, bunga tunggal, persentase, bruto, netto, tara) 4.9 Menyelesaikan masalah berkaitan dengan aritmatika sosial (penjualan, pembelian, potongan, keuntungan, kerugian, bunga tunggal, persentase, bruto, neto, tara). Penjabaran materinya sebagai berikut:

1) Harga penjualan, harga pembelian, keuntungan dan kerugian

2) Persentase untung dan rugi

3) Bruto, tara dan netto

4) Rabat (diskon)

5) Bunga Tunggal

Selain perangkat pembelajaran, tes yang dikembangkan berdasarkan empat aspek perumusan indikator kemampuan pemecahan masalah matematis terkait dengan materi aritmetika sosial. Adapun indikator yang digunakan adalah:

1) Memahami masalah

2) Membuat rencana penyelesaian.

3) Menyelesaikan rencana

4) Menyimpulkan

Tes yang dikembangkan berupa soal uraian berkaitan yang dengan permasalahan kontekstual yang sesuai dengan materi aritmatika sosial.

Validasi Perangkat yaitu penilaian draf rancangan awal perangkat pembelajaran Silabus, RPP, LKPD dan tes KPMM oleh para ahli atau validator. Hasil validasi Silabus disajikan pada Tabel 3.

Tabel 3. Hasil validasi silabus.

\begin{tabular}{cccc}
\hline No & $\begin{array}{c}\text { Aspek } \\
\text { yang } \\
\text { dinilai }\end{array}$ & $\begin{array}{c}\text { Rata- } \\
\text { rata } \\
(\boldsymbol{\%})\end{array}$ & Kriteria \\
\hline 1 & Tampilan & 91,67 & Sangat valid \\
2 & Isi & 86,25 & Sangat valid \\
3 & Konstruksi & 83,33 & cukup valid \\
Rata-rata Total & $87,08 \%$ & Sangat valid \\
Validitas RTV) & & \\
\hline
\end{tabular}

Berdasarkan Tabel 3 diperoleh rata-rata keseluruhan $87,08 \%$ dengan kategori sangat valid. Namun, terdapat beberapa saran untuk perbaikan, salah satunya pada bagian tampilan tidak terdapat identitas sekolah dan bagian sumber belajar belum lengkap seperti buku yang relevan, media, alat dan bahan yang digunakan. sehingga validator menyarankan untuk dilengkapi. Hasil dari validasi RPP disajikan pada Tabel 4.

Tabel 4. Hasil validasi RPP.

\begin{tabular}{|c|c|c|c|c|c|c|}
\hline \multirow{2}{*}{ No } & \multirow{2}{*}{ Aspek yang dinilai } & \multicolumn{5}{|c|}{ Hasil Penilaian (dalam \%) } \\
\hline & & RPP-1 & RPP-2 & RPP-3 & RPP-4 & RPP-5 \\
\hline 1 & Materi & 81,94 & 84,17 & 83,06 & 81,53 & 84,12 \\
\hline 2 & Penyajian & 91,67 & 89,06 & 88,54 & 91,15 & 88,54 \\
\hline 3 & $\begin{array}{l}\text { Penggunaan bahasa dan } \\
\text { keterbacaan }\end{array}$ & 86,11 & 83,33 & 86,11 & 86,11 & 86,11 \\
\hline Rat & ta-rata Total Validitas (RTV) & 86,75 & 85,52 & 85,91 & 86,26 & 86,26 \\
\hline Kri & iteria & $\begin{array}{c}\text { Sangat } \\
\text { valid }\end{array}$ & $\begin{array}{c}\text { Sangat } \\
\text { valid }\end{array}$ & $\begin{array}{c}\text { Sangat } \\
\text { valid }\end{array}$ & $\begin{array}{c}\text { Sangat } \\
\text { valid }\end{array}$ & $\begin{array}{c}\text { Sangat } \\
\text { valid }\end{array}$ \\
\hline
\end{tabular}


DOI: https://doi.org/10.24127/ajpm.v9i3.2957

Berdasarkan Tabel 4 diperoleh rata-rata keseluruhan $86,10 \%$ dengan kategori sangat valid. Namun, terdapat beberapa saran untuk perbaikan, salah satunya pada bagian kegiatan inti yang setiap pertemuan hampir sama yaitu hanya menggunakan kata-kata pada
LKPD dan tidak disebutkan LKPD yang berkaitan dengan materi yang akan dibahas, sehingga validator menyarankan untuk diubah dan disertai dengan materi yang akan disampaikan pada pertemuan tersebut.

Tabel 5. Hasil validasi LKPD.

\begin{tabular}{clccccc}
\hline \multirow{2}{*}{ No } & \multirow{2}{*}{ Aspek yang dinilai } & \multicolumn{5}{c}{ Hasil Penilaian (dalam \%) } \\
\cline { 2 - 6 } & LKPD-1 & LKPD-2 & LKPD-3 & LKPD-4 & LKPD-5 \\
\hline 1 & Tampilan & 92,86 & 92,26 & 94,05 & 94,64 & 94,64 \\
2 & Materi & 82,04 & 81,50 & 82,54 & 83,88 & 81,94 \\
3 & Bahasa dan keterbacaan & 84,38 & 80,90 & 79,86 & 84,38 & 82,29 \\
Rata-rata Total Validitas & 86,43 & 84,89 & 85,48 & 87,63 & 86,29 \\
Kriteria & Sangat & Sangat & Sangat & Sangat & Sangat \\
& valid & valid & valid & valid & valid \\
\hline
\end{tabular}

Selanjutnya, untuk hasil validasi LKPD disajikan pada Tabel 5. Berdasarkan Tabel 5 diperoleh rata-rata keseluruhan $86,14 \%$ artinya LKPD yang dikembangkan dikategorikan sangat valid. Pada indikator bahasa dan materi, validator memberi penilaian sedikit rendah dari lainnya dikarenakan penggunaan bahasa pada soal LKPD masih membuat peserta didik kebingungan memahaminya karena penyajiannya terlalu panjang. Ketiga validator menyimpulkan bahwa LKPD dapat digunakan dengan revisi kecil.

Sedangkan hasil validasi instrument tes kemampuan pemecahan masalah matematis disajikan pada Tabel 6. Berdasarkan Tabel 6 diperoleh ratarata keseluruhan $85,42 \%$ artinya instrumen tes kemampuan pemecahan masalah matematis berada pada kategori sangat valid. Namun demikian terdapat beberapa yang harus direvisi yaitu soal yang terlalu panjang wacananya sehingga akan membuat peserta didik malas untuk membaca. Kemudian bahasa pada soal masih belum komunikatif sehingga pertanyaan dari soal belum bisa dipahami peserta didik.
Tabel 6. Hasil validasi tes kemampuan pemecahan masalah matematis.

\begin{tabular}{|c|c|c|c|}
\hline No & $\begin{array}{c}\text { Aspek yang } \\
\text { dinilai }\end{array}$ & $\begin{array}{l}\text { Rata- } \\
\text { rata }\end{array}$ & Kriteria \\
\hline 1 & Materi & $81,25 \%$ & $\begin{array}{l}\text { Cukup } \\
\text { valid }\end{array}$ \\
\hline 2 & Konstruksi & $91,67 \%$ & $\begin{array}{l}\text { Sangat } \\
\text { valid }\end{array}$ \\
\hline 3 & Bahasa & $83,33 \%$ & $\begin{array}{l}\text { Cukup } \\
\text { valid }\end{array}$ \\
\hline \multicolumn{2}{|c|}{$\begin{array}{l}\text { Rata-rata Total } \\
\text { Validitas (RTV) }\end{array}$} & $85,42 \%$ & $\begin{array}{l}\text { Sangat } \\
\text { valid }\end{array}$ \\
\hline
\end{tabular}

\section{Uji coba pengembangan}

Setelah revisi validasi perangkat, maka perangkat akan diuji cobakan kelompok kecil. Uji coba dilakukan kepada 6 orang peserta didik dengan memberikan LKPD dan angket respon kepada masing-masing peserta didik untuk diisi setelah peserta didik selesai menjawab LKPD. Adapun hasil angket respon peserta didik terhadap keterbacaan LKPD disajikan pada Tabel 7. Berdasarkan Tabel 7 diperoleh ratarata keseluruhan $94,61 \%$ artinya keterbacaan LKPD berbasis model PBL pada materi aritmetika sosial ini sangat praktis digunakan oleh peserta didik. 
DOI: https://doi.org/10.24127/ajpm.v9i3.2957

Tabel 7. Hasil Keterbacaan LKPD

\begin{tabular}{|c|c|c|c|c|c|c|}
\hline \multirow{2}{*}{ No } & \multirow{2}{*}{ Aspek yang dinilai } & \multicolumn{5}{|c|}{ Hasil Penilaian (dalam \%) } \\
\hline & & LKPD 1 & LKPD 2 & LKPD 3 & LKPD 4 & LKPD 5 \\
\hline 1 & Tampilan & 95,83 & 93,75 & 95,83 & 95,83 & 95,83 \\
\hline 2 & Materi & 93,23 & 93,72 & 94,79 & 95,31 & 94,27 \\
\hline 3 & Bahasa & 95,75 & 95,83 & 93,75 & 93,75 & 91,67 \\
\hline \multirow{2}{*}{\multicolumn{2}{|c|}{$\begin{array}{l}\text { Rata-rata Persentase } \\
\text { keseluruhan }(\%) \\
\text { Kriteria }\end{array}$}} & 94,94 & 94,43 & 94,79 & 94,96 & 93,92 \\
\hline & & $\begin{array}{l}\text { Sangat } \\
\text { praktis }\end{array}$ & $\begin{array}{l}\text { Sangat } \\
\text { praktis }\end{array}$ & $\begin{array}{l}\text { Sangat } \\
\text { praktis }\end{array}$ & $\begin{array}{l}\text { Sangat } \\
\text { praktis }\end{array}$ & $\begin{array}{l}\text { Sangat } \\
\text { praktis }\end{array}$ \\
\hline
\end{tabular}

Berdasarkan analisis hasil validasi pada penelitian ini bahwa perangkat pembelajaran matematika berupa Silabus, RPP, LKPD dan Soal Kemampuan Pemecahan Masalah Matematis pada materi arimetika sosial menggunakan model Problem Based Learning sudah memenuhi kriteria valid dan praktis, sehingga dinyatakan bahwa Perangkat tersebut dapat digunakan dalam pembelajaran matematika pada materi aritmetika sosial.

Nieveen (Novrini, dkk, 2015) menyatakan bahwa perangkat pembelajaran dikatakan memiliki kualitas yang baik apabila perangkat tersebut valid dan praktis. Berdasarkan uraian hasil validasi terhadap Silabus, RPP, LKPD dan Tes Kemampuan Pemecahan Masalah Matematis untuk materi Aritmetika Sosial dapat disimpulkan bahwa perangkat pembelajaran yang dikembangkan telah memenuhi kriteria kevalidan. Berdasarkan lembar observasi angket respon peserta didik terhadap penggunaan LKPD dapat disimpulkan bahwa LKPD telah memenuhi kriteria praktis.

Hasil ini sejalan dengan penelitian yang dilakukan Fitratul (2017) pada kelas VIII SMP. Hasil penelitian menunjukan perangkat pembelajaran matematika yang dikembangkan masing-masing memenuhi kriteria valid dengan kategori "baik" dan memenuhi kriteria praktis dengan kategori "sangat baik" berdasarkan respon peserta didik.

\section{KESIMPULAN DAN SARAN}

Penelitian ini menghasilkan produk pengembangan perangkat pembelajaran berbasis PBL pada materi pokok Aritmetika Sosial untuk memfasilitasi Kemampuan Pemecahan masalah matematis telah memenuhi kriteria valid dan praktis. Kategori dan kdua kriteria tersebut adalah sangat valid, dan sangat praktis. Saran untuk penelitian selanjutnya, yaitu dapat melakukan pengembangan prangkat pembelajaran matematika ini pada skala yang lebih luas yaitu untuk melihat efektivitas.

\section{DAFTAR PUSTAKA}

Agrawal, J., \& Morin, L. L. (2016). Evidence-Based Prectise: Aplications of Concrete Representational Abstract Framework across Math Concepts for Students with Mathematics Disabilities. Learning Disabilities Research and Practice, 31(I), 3444.

Akbar, S. (2013). Instrumen Prangkat Pembelajaran. Bandung: PT. Remaja Rosdakarya.

Amri. S, (2013). Pengembangan Perangkat Pembelajaran 
DOI: https://doi.org/10.24127/ajpm.v9i3.2957

Matematika Berbasis Masalah Pada Materi Aritmetika Sosial Untuk Siswa Kelas VII. Jurnal Pendidikan Matematika, 6(5).

Arjudin, Sutawdjaja, A., Irawan, E. B., \& Sa'adijah, C. (2016). Characterization of mathematical Conection Errors in Derivative problem solving. IOSR Jounal of Research \& Method in Education, 6(5), 7-12. http://doi.org/10.9790/73880605050712.

Choridah, (2013).

Perangkat Pembelajaran Matematika Bercirikan PBL untuk Mengembangkan HOTS Siswa SMA. Jurnal Riset Pendidikan Matematika. 189-197

Dindyal, J., Guan, T. E., Lam, T.T., Hoong, L. Y., \& Seng Q. K. (2012). Mathematical Problem Solving for Everyone: A New Beginning. The Mathematics Educator, 13(2), 1-20.

Fitratul, W. (2017). Pengembangan Perangkat Pembelajaran Berbasis Masalah Berorientasi pada Kemampuan Komunikasi dan Prestasi Belajar Matematika Siswa SMP. Jurnal Riset Pendidikan Matematika, 4 (1), 3242.

Garcia, T., \& Boom, J., Krosbergen, E. Nunez, J.C., \& Rodriguez, C. (2019). Planning, Execution, and Revision in Mathematics Problem Solving: Does the Order of the Phases Matter? Studies in Educational Evaluation, 83-89. http://doi.org/10.1016/j.stueduc.2 $\underline{019.03 .001}$.
Haryani, S., Wardani, S., \& Prasetya, A. T. (2015). Development of Chemsitry Teacher Profesionalism through Pedagogical Content Knowledge Training. Sainteknol, 14(2), 139150.

Heriyadi, R.C.I.P. (2020). Pengembangan Lembar Kerja Siswa menggunakan Pendekatan Matematika Realistik. AKSIOMA: Jurnal Program Studi Pendidikan Matematika, 9(2), 395-412.

Indriani, K. W. A. (2017). Analisis Kualitas perancangan RPP dengan Menggunakan Kerangka Kerja ELPSA pada Focused Group Discussion di Kabupaten Sumbawa Barat. Jurnal Didaktik Matematika, 4185, 25-34
Mulyatiningsih,
E.
(2014). Pengembangan Perangkat Pembelajaran Aritmetika Sosial Berbasis Problem Based Learning di kelas VII SMP. Jurnal Elemen, 2 (2), 92-115.

Novia. V, et all (2016). Kemampuan Pemecahan Masalah dan Komunikasi Matematis Peserta didik Menyelesaikan Soal Cerita Materi Pecahan di SMP. Jurnal Mosharafa, 2(6), 86-104.

Novrini. P, \& Edy. S, (2015). Pengembangan Perangkat Pembelajaran Berorientasi Problem Based Learning Untuk Meningkatkan Kemampuan Pemecahan Masalah Matematis Siswa Kelas VIII SMP. Jurnal Paradigma, 8(3), 84-97 
DOI: https://doi.org/10.24127/ajpm.v9i3.2957

Ramirez, G., Shaw, S., T., \& Maloney, E. A. (2018). Math Anxiety: Past Research, Promising Interventions, and a New Interpetation Framework. Educational Psychologist, O(0), 120.

https://doi.org/10.1080/00461520. 2018.1447384.

Syawahid, M., \& Putrawangsa, S. (2017). Kemampuan Literasi Matematika Siswa SMP ditinjau dari gaya Belajar. Beta Jurnal tadris Matematika, 10(2), 222240.
Wahyuni, D., Masykur, R., \& Pratiwi, D. D. (2019). Pengembangan Multimedia Pembelajaran Matematika dengan Pendekatan Matematika Realistik. AKSIOMA: Jurnal Program Studi Pendidikan Matematika, 8(1), 32-40. 